Syntax Literate: Jurnal Ilmiah Indonesia p-ISSN: 2541-0849

e-ISSN: 2548-1398

Vol. 6, No. 7, Juli 2021

\title{
ANALISIS KONDISI KERUSAKAN JARINGAN IRIGASI SETUPATOK KABUPATEN CIREBON
}

\section{Sonie Apriyanto}

Sekolah Tinggi Teknologi (STT) Cirebon Jawa Barat, Indonesia

Email: sonieapriyanto@gmail.com

\begin{abstract}
Abstrak
Penelitian ini bertujuan untuk menganalisis kondisi kerusakan bangunan dan saluran induk serta kebocoran yang terjadi di sepanjang saluran induk Daerah Irigasi Setupatok, pada penelitian ini dilaksanakan dengan cara penelusuran saluran induk argasunya dan saluran induk Luwung di dasarkan pada Peraturan Menteri Pekerjaan Umum dan Perumahan Rakyat Nomer 12/PRT/M/2015 Tentang eksploitasi dan pemeliharaan jaringan irigasi pada bab 11.2.9 yang menjelaskan tentang Kondisi Kerusakan Jaringan Irigasi, sedangkan untuk kebocoran air pada saluran Induk Daerah Irigasi Setupatok menggunakan perhitungan fluida dinamis. Hasil analisis menunjukan bahwa Kondisi Kerusakan Bangunan dan Saluran Induk Argasunya kondisi baik 71,19\%, kondisi rusak ringan 1,01\%, kondisi rusak sedang $22.44 \%$, kondisi rusak berat $5.31 \%$. dan Saluran Induk Luwung kondisi baik 56,19\%, kondisi rusak sedang $6.80 \%$, kondisi rusak berat 37,02 \%. untuk kondisi kebocoran air pada saluran induk Argasunya dan induk Luwung sebesar 330 liter / detik.
\end{abstract}

Kata Kunci: jaringan irigasi setupatok; kondisi kerusakan

\section{Abstract}

This study aims to analyze the condition of damage to buildings and main canals and leaks that occur along the main canal of the Irrigation Area of Setupatok, in this study carried out by tracing the buildings and main lines of the Argasunya and Luwung main canals based on the Regulation of the Minister of Public Works and Public Housing Number 12 / PRT / M / 2015 Regarding the exploitation and maintenance of irrigation networks in chapter 11.2.9 which describes Irrigation Network Damage Conditions, while for water leakage in channels using dynamic fluid calculations. Results of analysis showed that the condition of building damage and the parent channel is good condition of 71,19\%, condition of damaged mild $1,01 \%$, damaged condition is $22.44 \%$, the condition is severely damaged $5.31 \%$. and Luwung mains line good condition $56,19 \%$, damaged condition is 6,80\%, the condition is severely damaged 37,02 \%. For the water leakage condition of the Argasunya mains and parent Luwung at 330 liters/sec.

Keywords : setupatok irrigation network; broken conditions

$\begin{array}{ll}\text { How to cite: } & \text { Apriyanto, Sonie (2021) Analisis Kondisi Kerusakan Jaringan Irigasi Setupatok Kabupaten Cirebon. Syntax } \\ & \text { Literate: Jurnal Ilmiah Indonesia. 6(7). http://dx.doi.org/10.36418/ syntax-literate.v6i7.3510 } \\ \text { E-ISSN: } & \text { 2548-1398 } \\ \text { Published by: } & \text { Ridwan Institute }\end{array}$




\section{Pendahuluan}

Air merupakan sumber utuma kehidupan, Air di gunakan dalam bermacam aspek kebutuhan mulai dari minum, mandi, mencuci hingga mengairi sawah (Ariyantini, 2017). Berdasarkan Peraturan Pemerintah No. 21 Tahun 1982 dijelaskan bahwa Pengurusan dan pengaturan air Irigasi dan Jaringn irigasi beserta bangunan pelengkapnya yang ada di dalam wilayah Daerah, diserahkan kepada Pemerintah Daerah yang bersangkutan dengan berpedoman pada ketentuan-ketentuan dalam undang-undang maka di Desa Setupatok Kecamatan Mundu Kabupaten Cirebon Provinsi Jawa Barat telah dibangun Bendungan Setupatok dan Jaringan Irigasi, agar dimanfaatkan untuk kebutuhan air Irigasi di beberapa Sub Daerah Irigasi di sekitarnya dengan luas areal 1.365 Ha. Jaringan Irigasi Setupatok mengalir di dua saluran induk yaitu saluran Induk luwung dan saluran Induk Argasunya yang masing masing memililki Bangunan Irigasi dan saluran irigasi. seiring berjalanya waktu usia Bangunan dan saluran irigasi banyak yang mengalami kerusakan khususnya pada saluran induk argasunya dan saluran induk luwung serta kebocoran saluran maka perlu dilakukan penelitian Analisis Kondisi Kerusakan Jaringan Irigasi Setupatok.

Jaringan irigasi adalah saluran, bangunan dan bangunan pelengkapnya yang merupakan satu kesatuan dan diperlukan untuk pengaturan air irigasi mulai dari penyediaan pengambilan, pembagian pemberian penggunaan dan pembuangannya, secara hirarki jaringan irigasi dibagi menjadi jaringan utama dan jaringan tersier Jaringan utama adalah jaringan irigasi yang berada dalam satu sistem irigasi, mulai dari bangunan utama, saluran induk atau primer, saluran sekunder, dan bangunan sadap serta bangunan pelengkapnya (Bunganaen, 2011), Jaringan tersier adalah jaringan irigasi yang berfungsi sebagai perasarana pelayanan air di dalam petak tersier yang terdiri dari saluran pembawa yang disebut saluran tersier, saluran pembagi yang disebut saluran kuarter dan saluran pembuang berikut saluran bangunan turutan serta pelengkapnya, termasuk jaringan irigasi pompa, yang luas areal pelayanannya disamakan dengan areal tersier (Azrun, 2019). Berdasarkan hasil inventarisasi dilakukan survei kondisi kerusakan dan kebutuhan pemeliharaan secara partisipatif, dan dibuat suatu rangkaian rencana aksi yang tersusun dengan skala prioritas. Dalam menentukan kriteria kerusakan phisik Jaringan irigasi. Pada hakekatnya pemeliharaan jaringan irigasi yang tertunda akan mengakibatkan kerusakan yang lebih parah dan memerlukan rehabilitasi lebih dini. Klasifikasi kondisi fisik jaringan irigasi pada bangunan irigasi sebagai berikut (Anonim, 2015):

\section{Tabel 1}

Tingkatan Penilaian Kondisi

\begin{tabular}{|c|c|c|c|c|c|c|}
\hline \multirow{2}{*}{ Komponen } & \multicolumn{6}{|c|}{ Nilai Kondisi } \\
\hline & 1 & 2 & & 3 & & 4 \\
\hline (1) & (2) & (3) & & (4) & & (5) \\
\hline Saluran: & Baik: & Rusak Ring & & Rusak Sed & & Rusak Berat: \\
\hline $\begin{array}{l}\text { Tanggul pasangan } \\
\text { lining (tipe lining) } \\
\text { plesteran }\end{array}$ & $\begin{array}{l}\text { Secara structural, } \\
\text { dimensinya tidak } \\
\text { berubah bentuk. }\end{array}$ & $\begin{array}{l}\text { Bangunan } \\
\text { kondisi } \\
\text { dimensinya }\end{array}$ & $\begin{array}{r}\text { dan } \\
\text { baik, }\end{array}$ & $\begin{array}{l}\text { Penurunan } \\
\text { signifikan } \\
\text { bangunan }\end{array}$ & $\begin{array}{r}\text { yang } \\
\text { pada } \\
\text { dan }\end{array}$ & $\begin{array}{l}\text { Masalah bangunan } \\
\text { yang serius } \\
\text { menyebabkan akan }\end{array}$ \\
\hline
\end{tabular}




\begin{tabular}{|c|c|c|c|c|}
\hline & $\begin{array}{l}\text { Tidak ada } \\
\text { kerusakan, } \\
\text { gebalan rumput } \\
\text { dan endapan } \\
\text { lumpu }\end{array}$ & $\begin{array}{lr}\text { tapi } & \text { endapan } \\
\text { lumpur } & \text { yang } \\
\text { secara signifikan } & \text { mempengaruhi } \\
\text { memgsionalnya }\end{array}$ & $\begin{array}{l}\text { perubahan bentuk } \\
\text { dimensinya, } \\
\text { membutuhkan } \\
\text { perbaikan urgent }\end{array}$ & $\begin{array}{l}\text { roboh, sehingga } \\
\text { dibutuhkan } \\
\text { perbaikan } \\
\text { kontruksi setengah } \\
\text { atau seluruhnya }\end{array}$ \\
\hline \multirow{7}{*}{$\begin{array}{l}\text { Bangunan } \\
\text { pengatur: } \\
\text { Struktue sayap } \\
\text { huku sayap hilir } \\
\text { papan eksploitasi } \\
\text { bagian pengatur }\end{array}$} & Baik: & Rusak Ringan: & Rusak Sedang: & Rusak Berat: \\
\hline & Secara structural & Secara umum baik & Berdasarkan & Kerusakan \\
\hline & tidak & tapi sedikit & struktur & serius \\
\hline & perubahan baik & kerusakan & dimensinya lebih & strukturnya \\
\hline & dimensi maupun & struktur & buruk dari 1 tingkat & menyebabkan \\
\hline & profilnya. Tanpa & dimensi & dan dengan lumpur & keruntuhan dalam \\
\hline & endapan lumpur & berdampak pada & yang berdampak & waktu dekatdan \\
\hline \multirow[t]{2}{*}{ Peilscall } & ada, dipastikan & fungsinya. Banyak & pada fungsi & perbaikan ulang \\
\hline & aman dan siap & endapan lumpur & bangunan ada, tapi & kontruksinya tidak \\
\hline \multirow[t]{7}{*}{ Nomenklatur } & dipakai aman, & ada, & tidak terbaca jelas & ada peilscall/tidak \\
\hline & tidak rusak, dan & pembacaannya & dan terdapat & terbaca/tidak dapat \\
\hline & siap digunakan & sulit pada saat & tampilan tanda & dipercaya \\
\hline & & beberapa kondisi & pengukurannya ada & nomenklaturnya \\
\hline & & secara umum & nomenklatur & tidak diperbaharui, \\
\hline & & kondisinya baik & tidak pasti & rusak atau tidak \\
\hline & & tapi sulit dibaca & kepercayaannya. & dapat terbaca \\
\hline
\end{tabular}

Sumber: (Eyben, 2003)

Nilai dari hasil perhitungan kondisi fisik akan dianalisis tingkat kerusakannya menggunakan tabel 2. Persentase kerusakan aset dalam empat kriteria yaitu kerusakan baik, rusak ringan, sedang, dan berat.

$\mathrm{K}=\frac{\mathbf{A}_{\boldsymbol{k}}}{\mathbf{A}_{\mathrm{ka}}} \times 100 \%$

Keterangan :

$\mathrm{K}=$ Kondisi $(\%)$

$\mathrm{Ak}=$ Luas Kerusakan

Aka $=$ Luas Total Aset

Menurut (Sari, 2015) untuk mengetahui Persentase Tingkat Kondisi Kerusakan aset dijelaskan pula dalam bentuk persentase angka, sehingga lebih memudahkan dalam menghitung keberfungsiannya.

\section{Tabel 2}

Persentase Tingkat Kondisi Kerusakan

\begin{tabular}{lcc}
\multicolumn{1}{c}{ Kondisi } & Indeks Kerusakan & Skor K \\
\hline Baik & $<10 \%$ & 4 \\
\hline Rusak Ringan & $10-20 \%$ & 3 \\
\hline Rusak Sedang & $20-40 \%$ & 2 \\
\hline Berat & $>40 \%$ & 1 \\
\hline
\end{tabular}

Sumber: Peraturan Menteri Pekerjaan Umum (Anonim, 2015)

Rumus dasar fluida dinamis menurut (Widodo, Suharno, \& Salahudin, 2016) yaitu sebagai berikut:

a) Kecepatan aliran adalah hasil bagi antara jarak lintasan dengan waktu tempuh atau bisa dituliskan dengan persamaan (Norhadi, Marzuki, Wicaksono, \& Yacob, 2015):

$$
\mathrm{V}=\mathrm{L} / \mathrm{T}
$$


Keterangan :

$\mathrm{V}=$ kecepatan $(\mathrm{m} / \mathrm{s})$

$\mathrm{L}=$ panjang lintasan $(\mathrm{m})$

$\mathrm{t}=$ waktu tempuh (s)

b) Debit air mampu dihitung dengan menggunakan rumus sebagai berikut:

$\mathrm{Q}=\mathrm{VxA}$

Keterangan rumus:

$\mathrm{Q}$ adalah Debit aliran $\left(\mathrm{m}^{3} / \mathrm{s}\right)$

A adalah Luas penampang $\left(\mathrm{m}^{2}\right)$

$\mathrm{V}$ adalah Kecepatan aliran $(\mathrm{m} / \mathrm{s})$

c) Luas penampang adalah luas permukaan bidang datar rata yang berbentuk lingkaran.

Sehingga mencari luas penampang sama dengan luas lingkaran, yaitu :

$\mathrm{A}=\pi \cdot \mathrm{r}^{2}$

Keterangan rumus:

A adalah luas penampang $\left(\mathrm{m}^{2}\right)$

$\pi$ adalah $(22 / 7)$

$\mathrm{r}$ adalah jari-jari lingkaran (m)

\section{Metode Penelitian}

Metode yang diterapkan dalam studi ini adalah deskriptif kuantitatif (Cresswell, 2017), yaitu mangadakan penelitian menggunakan data sekunder dari variabel yang diteliti (Sugiyono, 2015). Studi ini melibatkan beberapa parameter yang digunakan untuk pertimbangan dalam pengambilan keputusan. Parameter tersebut antara lain: mengumpulkan dan mempelajari literatur yang berkaitan dengan perencanaan.

Pengumpulan data dilakukan untuk memperoleh informasi yang dibutuhkan dalam rangka mencapai tujuan penelitian.

a) Data Primer

Data primer adalah data yang diperoleh dari data rencana pembangunan ataupun data hasil survei yang dapat digunakan langsung dalam Identifikasi yang akan di lakukan yaitu sebagai berikut (Kogoya, Olfie, \& Laoh, 2015):

- Data Sekema Bangunan Irigasi Daerah Irigasi Setupatok

- Data Skema Jaringan Irigasi Daerah Irigasi Setupatok.

b) Data Sekunder

Data sekunder merupakan data penunjang dalam mengidentifikasi yang didapat baik dari laporan-laporan instansi terkait atau literatur maupun lembaga lain yang mendukung kegiatan penelitian ini dapun data-data sekunder yang di peroleh untuk analisis ketersediaan air irigasi dan kebutuhan air irigasi sebagai berikut:

- Data kerusakan bangunan bangunan air yang terjadi pada Saluran Irigasi Induk Argasunya dan Induk luwung Daerah irigasi Setupatok.

- Data kerusakan Pintu-pintu air yang terjadi pada saluran Irigasi Induk Argasunya dan Induk luwung Daerah Irigasi Setupatok. 
c) Teknik Pengambilan Sampel

- Survei lokasi Sesuai sekema Bangunan Irigasi Setupatok.

- Mencatat kerusakan Bangunan dan Saluran D.I. Setupatok.

- Mengukur keruskan Bangunan dan Saluran D.I. Setupatok.

- Dokumentasikan kerusakan Bangunan dan Saluran D.I. Setupatok.

- Masukan data ke dalam Perangkat Lunak : Microsoft Office Excel 2010.

- Menganalisis Kondisi kerusakan Bangunan dan Saluran D.I. Setupatok.

- Menganalisis Kebocoran pada Saluran Induk D.I. Setupatok.

d) Metode Analisis

- Pelaksanaan penelitian.

- Menentukan jenis kerusakan Saluran Induk Argasunya dan Saluran Induk luwung Daerah Irigasi Setupatok.

- Menganalisis jenis kerusakan Bangunan Irigasi Induk Argasunya dan Bangunan Irigasi Induk luwung Daerah Irigasi Setupatok.

- Menganalisis tingkat jenis kerusakan (score/bobot) Saluran Induk Argasunya dan Saluran Induk luwung Daerah Irigasi Setupatok.

- Menganalisis tingkat kerusakan (score/bobot) Bangunan Irigasi Induk Argasunya dan Induk luwung Daerah Irigasi Setupatok.

- Menganalisis Kebocoran yang terjadi pada Saluran Induk Daerah Irigasi Setupatok.

\section{Hasil dan Pembahasan}

Analisis kondisi kerusakan jaringan di lakukan di dua saluran induk D.I Setupatok sebagai berikut :

A. Tabel hasil analisis kondisi kerusakan jaringan pada Saluran Induk Argasunya D.I Setupatok

Tabel 3

Analisis kondisi kerusakan Saluran Induk Argasunya

\begin{tabular}{|c|c|c|c|c|c|c|c|c|}
\hline \multirow[b]{2}{*}{ Uraian } & \multicolumn{8}{|c|}{ Kondisi Saluran } \\
\hline & Baik & $\begin{array}{c}\% \\
\text { Km }\end{array}$ & $\begin{array}{l}\text { Rusak } \\
\text { Ringan } \\
<10\end{array}$ & $\begin{array}{l}\% \\
10-20\end{array}$ & $\begin{array}{l}\text { Rusak } \\
\text { Sedang } \\
\text { Km }\end{array}$ & $\begin{array}{l}\% \\
21-40\end{array}$ & $\begin{array}{l}\text { Rusak } \\
\text { Berat } \\
\text { Km }\end{array}$ & $\begin{array}{l}\% \\
>40\end{array}$ \\
\hline $\begin{array}{l}\text { Saluran Induk } \\
\text { Argasunya }\end{array}$ & & & & & & & & \\
\hline $\begin{array}{l}\text { Ruas situpatok-B.As } \\
1\end{array}$ & & & & & & & & \\
\hline 0.22 & 0.21 & 94.05 & & & & & 0.01 & 5.95 \\
\hline Ruas B.As 1-B.As 2 & & & & & & & & \\
\hline 0.22 & 0.20 & 91.03 & 0.02 & 8.97 & & & & \\
\hline Ruas B.As 2-B.As 3 & & & & & & & & \\
\hline 0.59 & 0.53 & 90.80 & 0.01 & 1.87 & & & 0.04 & 7.33 \\
\hline Ruas B.As 3-B.As 4 & & & & & & & & \\
\hline 0.29 & 0.27 & 92.98 & & & 0.02 & 7.02 & & \\
\hline Ruas B.As 4-B.As 5 & & & & & & & & \\
\hline 0.30 & 0.22 & 73.60 & & & 0.08 & 26.40 & & \\
\hline Ruas B.As 5-B.As 6 & & & & & & & & \\
\hline 1.12 & 0.04 & 33.88 & & & 0.08 & 66.12 & & \\
\hline
\end{tabular}




\begin{tabular}{lllllll}
\hline Ruas B.As 6-B.As 7 & \multicolumn{7}{l}{} \\
\hline 0.25 & 0.12 & 47.79 & 0.04 & 16.06 & 0.09 & 36.14 \\
\hline Ruas B.As 7-B.As 8 & & & & & & \\
\hline 0.78 & 0.38 & 48.98 & 0.40 & 51.02 & & \\
\hline Ruas B.As 8-B.As 9 & & & & & & \\
\hline 0.17 & 0.12 & 70.06 & 0.04 & 23.95 & 0.01 & 5.99 \\
\hline
\end{tabular}

\section{B. Tabel hasil analisis kondisi kerusakan jaringan pada Saluran Induk Luwung D.I Setupatok}

Tabel 4

Analisis kondisi kerusakan Saluran Induk Luwung

\begin{tabular}{|c|c|c|c|c|c|c|c|c|}
\hline \multirow[b]{2}{*}{ Uraian } & \multicolumn{8}{|c|}{ Kondisi Saluran } \\
\hline & Baik & $\begin{array}{l}\% \\
\text { Km } \\
\end{array}$ & $\begin{array}{l}\text { Rusak } \\
\text { Ringan } \\
<10 \\
\end{array}$ & $\begin{array}{l}\% \\
10-20 \\
\end{array}$ & $\begin{array}{l}\text { Rusak } \\
\text { Sedang } \\
\text { Km } \\
\end{array}$ & $\begin{array}{l}\% \\
21-40 \\
\end{array}$ & $\begin{array}{l}\text { Rusak } \\
\text { Berat } \\
\text { Km } \\
\end{array}$ & $\begin{array}{l}\% \\
>40 \\
\end{array}$ \\
\hline $\begin{array}{l}\text { Saluran Induk } \\
\text { Luwung }\end{array}$ & & & & & & & & \\
\hline $\begin{array}{l}\text { Ruas situpatok-B.As } \\
1\end{array}$ & & & & & & & & \\
\hline 0.530 & 0.52 & 97.26 & & & & & 0.01 & 2.74 \\
\hline $\begin{array}{l}\text { Ruas B.Lw 1-B. } \\
\text { Lw2 }\end{array}$ & & & & & & & & \\
\hline 0.570 & 0.47 & 82.46 & & & & & 0.10 & 17.54 \\
\hline $\begin{array}{l}\text { Ruas B. Lw 2-B. Lw } \\
3\end{array}$ & & & & & & & & \\
\hline 0.100 & 0.07 & 69.00 & & & & & 0.03 & 31.00 \\
\hline $\begin{array}{l}\text { Ruas B. Lw 3-B. Lw } \\
4\end{array}$ & & & & & & & & \\
\hline 0.631 & 0.51 & 80.98 & & & & & 0.12 & 19.02 \\
\hline $\begin{array}{l}\text { Ruas B. Lw 4-B. Lw } \\
5\end{array}$ & & & & & & & & \\
\hline 0.399 & 0.10 & 24.81 & & & & & 0.30 & 75.19 \\
\hline $\begin{array}{l}\text { Ruas B. Lw 5-B. Lw } \\
6\end{array}$ & & & & & & & & \\
\hline 0.155 & 0.15 & 94.19 & & & & & 0.01 & 5.81 \\
\hline $\begin{array}{l}\text { Ruas B. Lw 6-B. Lw } \\
7\end{array}$ & & & & & & & & \\
\hline 0.639 & 0.46 & 71.83 & & & & & 0.18 & 28.17 \\
\hline $\begin{array}{l}\text { Ruas B. Lw 7-B. Lw } \\
8\end{array}$ & & & & & & & & \\
\hline 0.314 & 0.13 & 42.60 & & & & & 0.18 & 57.40 \\
\hline $\begin{array}{l}\text { Ruas B. Lw 8-B. Lw } \\
9\end{array}$ & & & & & & & & \\
\hline 0.082 & 0.00 & 2.37 & & & 0.04 & 48.82 & 0.04 & 48.82 \\
\hline $\begin{array}{l}\text { Ruas B. Lw 9-B. Lw } \\
10\end{array}$ & & & & & & & & \\
\hline 0.310 & & & & & 0.20 & 64.52 & 0.11 & 35.48 \\
\hline $\begin{array}{l}\text { Ruas B. Lw 10-B. } \\
\text { Lw } 11\end{array}$ & & & & & & & & \\
\hline 0.190 & & & & & 0.01 & 5.26 & 0.18 & 94.74 \\
\hline $\begin{array}{l}\text { Ruas B. Lw 8=11-B. } \\
\text { Lw } 12\end{array}$ & & & & & & & & \\
\hline 0.361 & 0.00 & & 0.00 & & 0.04 & 11.36 & 0.320 & 88.64 \\
\hline
\end{tabular}




\section{Tabel Akumulasi Kondisi Kerusakan Saluran Induk Argasunya D.I Setupatok}

Tabel 5

Akumulasi Kondisi Kerusakan Saluran Induk Argasunya

\begin{tabular}{|c|c|c|c|c|c|c|c|c|c|}
\hline \multirow[b]{2}{*}{ Jenis Infrastruktur } & \multicolumn{8}{|c|}{ Kondisi Saluran } & \multirow[b]{2}{*}{$\begin{array}{l}\% \\
>40\end{array}$} \\
\hline & $\begin{array}{l}\text { Panja } \\
\text { ng }\end{array}$ & Baik & $\begin{array}{l}\% \\
\text { Km }\end{array}$ & $\begin{array}{l}\text { Rusak } \\
\text { Ringa } \\
\mathbf{n} \\
<10 \\
\end{array}$ & $\begin{array}{l}\% \\
10-20\end{array}$ & $\begin{array}{l}\text { Rusak } \\
\text { Sedan } \\
\text { g } \\
\text { Km } \\
\end{array}$ & $\begin{array}{l}\% \\
21-40\end{array}$ & $\begin{array}{l}\text { Rusak } \\
\text { Berat } \\
\text { Km }\end{array}$ & \\
\hline \multicolumn{10}{|l|}{$\begin{array}{l}\text { Saluran Induk } \\
\text { Argasunya }(\mathrm{Km})\end{array}$} \\
\hline $\begin{array}{l}\text { Ruas situpatok-B.As } \\
1\end{array}$ & 0.22 & 0.21 & 94.05 & & & & & 0.01 & 5.95 \\
\hline Ruas B.As 1-B.As 2 & 0.22 & 0.20 & 91.03 & 0.02 & 8.97 & & & & \\
\hline Ruas B.As 2-B.As 3 & 0.59 & 0.53 & 90.80 & 0.01 & 1.87 & & & 0.04 & 7.33 \\
\hline Ruas B.As 3-B.As 4 & 0.29 & 0.27 & 92.98 & & & 0.02 & 7.02 & & \\
\hline Ruas B.As 4-B.As 5 & 0.30 & 0.22 & 73.60 & & & 0.08 & 26.40 & & \\
\hline Ruas B.As 5-B.As 6 & 1.12 & 0.04 & 33.88 & & & 0.08 & 66.12 & & \\
\hline Ruas B.As 6-B.As 7 & 0.25 & 0.12 & 47.79 & & & 0.04 & 16.06 & 0.09 & 36.14 \\
\hline Ruas B.As 7-B.As 8 & 0.78 & 0.38 & 48.98 & & & 0.40 & 51.02 & & \\
\hline Ruas B.As 8-B.As 9 & 0.17 & 0.12 & 70.06 & & & 0.04 & 23.95 & 0.01 & 5.99 \\
\hline
\end{tabular}

\section{Tabel Akumulasi Kondisi Kerusakan Saluran Induk Luwung D.I Setupatok}

\section{Tabel 6}

Akumulasi Kondisi Kerusakan Saluran Induk Luwung

\begin{tabular}{|c|c|c|c|c|c|c|c|c|c|}
\hline \multirow[b]{2}{*}{ Jenis Infrastruktur } & \multicolumn{8}{|c|}{ Kondisi Saluran } & \multirow[b]{2}{*}{$\begin{array}{l}\% \\
>40\end{array}$} \\
\hline & $\begin{array}{l}\text { Panja } \\
\text { ng }\end{array}$ & Baik & $\begin{array}{l}\% \\
\mathrm{Km}\end{array}$ & $\begin{array}{l}\text { Rusak } \\
\text { Ringa } \\
\mathbf{n} \\
<10\end{array}$ & $\begin{array}{l}\% \\
10-20\end{array}$ & $\begin{array}{l}\text { Rusak } \\
\text { Sedan } \\
\text { g } \\
\text { Km }\end{array}$ & $\begin{array}{l}\% \\
21-40\end{array}$ & $\begin{array}{l}\text { Rusak } \\
\text { Berat } \\
\text { Km }\end{array}$ & \\
\hline \multicolumn{10}{|l|}{$\begin{array}{l}\text { Saluran Induk } \\
\text { Luwung (Km) }\end{array}$} \\
\hline $\begin{array}{l}\text { Ruas situpatok-B.As } \\
1\end{array}$ & 0.530 & 0.52 & 97.26 & & & & & 0.01 & 2.74 \\
\hline Ruas B.As 1-B.As 2 & 0.570 & 0.47 & 82.46 & & & & & 0.10 & 17.54 \\
\hline Ruas B.As 2-B.As 3 & 0.100 & 0.07 & 69.00 & & & & & 0.03 & 31.00 \\
\hline Ruas B.As 3-B.As 4 & 0.631 & 0.51 & 80.98 & & & & & 0.12 & 19.02 \\
\hline Ruas B.As 4-B.As 5 & 0.399 & 0.10 & 24.81 & & & & & 0.30 & 75.19 \\
\hline Ruas B.As 5-B.As 6 & 0.155 & 0.15 & 94.19 & & & & & 0.01 & 5.81 \\
\hline Ruas B.As 6-B.As 7 & 0.639 & 0.46 & 71.83 & & & & & 0.18 & 28.17 \\
\hline Ruas B.As 7-B.As 8 & 0.314 & 0.13 & 42.60 & & & & & 0.18 & 57.40 \\
\hline Ruas B.As 8-B.As 9 & 0.082 & 0.00 & 2.37 & & & 0.04 & 48.82 & 0.04 & 48.82 \\
\hline $\begin{array}{l}\text { Ruas B.As 9-B.As } \\
10\end{array}$ & 0.310 & & & & & 0.20 & 64.52 & 0.11 & 35.48 \\
\hline $\begin{array}{l}\text { Ruas B.As 10-B.As } \\
11\end{array}$ & 0.190 & & & & & 0.01 & 5.26 & 0.18 & 94.74 \\
\hline $\begin{array}{l}\text { Ruas B.As 11-B.As } \\
12\end{array}$ & 0.361 & 0.00 & & 0.00 & & 0.04 & 11.36 & 0.320 & 88.64 \\
\hline
\end{tabular}




\section{E. Tabel Perhitungan Kebocoran dalam Pipa Pada Saluran Induk D.I Setupatok}

Tabel 7

perhitunga kebocoran dalam pipa pada Saluran Induk D.I Setupatok

\begin{tabular}{|c|c|c|c|c|c|c|c|}
\hline No & Nama & $\begin{array}{c}\text { Luas } \\
\text { Penampang } \\
\text { Pipa }(\mathrm{A})= \\
\left(\pi \mathbf{x r}^{2}\right) \mathbf{m}^{\mathbf{2}}\end{array}$ & $\begin{array}{l}\text { Waktu } \\
\text { (t) detik }\end{array}$ & $\begin{array}{c}\text { Pipa (r) } \\
\text { m }\end{array}$ & $\begin{array}{l}\text { Panjang } \\
\text { Pipa (L) }\end{array}$ & $\begin{array}{c}\text { Kecepatan } \\
\text { Aliran }(\mathbf{V})= \\
(\mathbf{L} / \mathbf{t}) \mathbf{m} / \text { detik }\end{array}$ & $\begin{array}{c}\text { Debit Aliran } \\
(\mathbf{Q})=(\text { A X } \\
\text { V) } \mathbf{m}^{3} / \text { detik }\end{array}$ \\
\hline 1 & & 0.0019625 & 0.7 & 0.025 & 3.2 & 4.571428571 & 0.008971429 \\
\hline 2 & & 0.0019625 & 0.8 & 0.025 & 5 & 6.25 & 0.012265625 \\
\hline 3 & & 0.00785 & 1.5 & 0.05 & 5 & 3.333333333 & 0.026166667 \\
\hline 4 & & 0.00785 & 1 & 0.05 & 3 & 3 & 0.02355 \\
\hline 5 & & 0.00785 & 1.5 & 0.05 & 3 & 2 & 0.0157 \\
\hline 6 & & 0.00785 & 1 & 0.05 & 3.2 & 3.2 & 0.02512 \\
\hline 7 & & 0.0019625 & 1 & 0.025 & 3.4 & 3.4 & 0.0066725 \\
\hline \multirow[t]{2}{*}{8} & & 0.0019625 & 1 & 0.025 & 3 & 3 & 0.0058875 \\
\hline & & & & & & Jumlah & 0.12433372 \\
\hline 1 & & 0.0019625 & 0.5 & 0.025 & 3 & 6 & 0.011775 \\
\hline 2 & & 0.0019625 & 0.5 & 0.025 & 3 & 6 & 0.011775 \\
\hline 3 & & 0.00785 & 0.5 & 0.05 & 3.2 & 6.4 & 0.05024 \\
\hline 4 & & 0.0019625 & 0.8 & 0.025 & 3 & 3.75 & 0.007359375 \\
\hline 5 & & 0.0019625 & 1.1 & 0.025 & 2.8 & 2.545454545 & 0.004995455 \\
\hline 6 & & 0.0019625 & 1.1 & 0.025 & 3.1 & 2.818181818 & 0.005530682 \\
\hline 7 & & 0.0019625 & 1.1 & 0.025 & 3 & 2.727272727 & 0.005352273 \\
\hline 8 & & 0.0019625 & 1.1 & 0.025 & 3.1 & 2.818181818 & 0.005530682 \\
\hline 9 & & 0.00785 & 1.1 & 0.05 & 3.3 & 3 & 0.02355 \\
\hline 10 & & 0.0019625 & 1.2 & 0.025 & 3 & 2.5 & 0.00490625 \\
\hline 11 & & 0.0019625 & 1.2 & 0.025 & 3.1 & 2.583333333 & 0.005069792 \\
\hline 12 & & 0.0019625 & 1.3 & 0.025 & 3 & 2.307692308 & 0.004528846 \\
\hline 13 & & 0.00785 & 1.2 & 0.05 & 3 & 2.5 & 0.019625 \\
\hline 14 & & 0.0019625 & 1.3 & 0.025 & 2.8 & 2.153846154 & 0.004226923 \\
\hline 15 & & 0.00785 & 1.4 & 0.05 & 3 & 2.142857143 & 0.016821429 \\
\hline 16 & & 0.0019625 & 1.4 & 0.025 & 2.9 & 2.071428571 & 0.004065179 \\
\hline 17 & & 0.0019625 & 1.4 & 0.025 & 3 & 2.142857143 & 0.004205357 \\
\hline 18 & & 0.0019625 & 1.5 & 0.025 & 2.7 & 1.8 & 0.0035325 \\
\hline 19 & & 0.0019625 & 1.5 & 0.025 & 2.8 & 1.866666667 & 0.003663333 \\
\hline 20 & & 0.0019625 & 1.5 & 0.025 & 2.9 & 1.933333333 & 0.003794167 \\
\hline 21 & & 0.0019625 & 1.7 & 0.025 & 2.8 & 1.647058824 & 0.003232353 \\
\hline \multirow[t]{3}{*}{22} & & 0.0019625 & 1.9 & 0.025 & 2.7 & 1.421052632 & 0.002788816 \\
\hline & & & & & & Jumlah & 0.20656841 \\
\hline & & & & & & Jumlah total & 0.33090213 \\
\hline
\end{tabular}

\section{Kesimpulan}

Berdasarkan analisis kondisi kerusakan yang telah dilakukan, maka didapat hasil kesimpulan bahwa kondisi Kerusakan Jaringan pada Saluran Induk Argasunya kondisi baik 71,19\%, kondisi rusak ringan 1,01\%, kondisi rusak sedang $22.44 \%$ dan kondisi rusak berat $5.31 \%$.Saluran Induk Luwung kondisi baik 56,19\%, kondisi rusak sedang $6.80 \%$ dan kondisi rusak berat 37,02\%.

Pengaruh kebocoran Saluran yang sengaja merusak saluran dan memasang pipa secara liar oleh para oknum yang tidak bertanggung jawab di antaranya terjadi kehilanga air sebesar 124 liter / detik pada saluran induk Argasunya dan 206 liter / detik 
pada saluran induk Luwung, membuat saluran mudah retak dan hancur, volume air yang di keluarkan menjadi tidak maksimal.

Saran yang dapat di berikan untuk Kerusakan Saluran Induk Argasunya dan saluran induk Luwung yaitu untuk kondisi baik agar di lakukan pemeliharaan rutin, untuk kondisi rusak ringan agar di lakukan pemeliharaan berkala yang bersifat perawatan, kondisi rusak sedang diperlukan pemeliharaan yang bersifat perbaikan struktur bangunan dan kondisi rusak berat agar di lakukan perbaikan secara segera karena banyak mengakibatkan kehilangan Air.

Untuk kerusakan yang di sebabkan oleh penyadapan pipa liar pada saluran induk Argasunya dan Saluran Induk luwung agar segera di tindak lanjuti dengan cara pendekatan secara langsung melalui sosialisasi antara oknum pengrusakan dengan P3A ( perkumpulan Petani Pemakai air ) di berikan arahan dan solusi agar bisa bersama sama saling menjaga dan merawat bangunan air untuk kepentingan bersama. 


\section{BIBLIOGRAFI}

Anonim. (2015). Peraturan Menteri Pekerjaan Umum Nomor: 12/PRT/M/2015 Tentang eksploitasi dan pemeliharuan jaringan irigasi.

Anonim. (2015). Peraturan Menteri Pekerjaan Umum Nomor 30/PRT/M 2015 Tentang Sistem Irigasi meliputi Prasarana irigasi, air irigasi, manajemen irigasi, kelembagaan pengelolaan irigasi dan sumber daya manusia .

Ariyantini, Mila Damanik. (2017). Digital Digital Repository Repository Universitas Universitas Jember Jember Staphylococcus aureus Digital Digital Repository Repository Universitas Universitas Jember Jember. Skripsi. Google Scholar

Azrun, Adim. (2019). Efisiensi Air Irigasi Pada Saluran Tersier di Daerah Irigasi Patula Desa Malaju Kecamatan Kilo Kabupaten Dompu. Universitas Muhammadiyah Mataram. Google Scholar

Bunganaen, Wilhelmus. (2011). Analisis Efisiensi Dan Kehilangan Air Pada Jariringan Utama Daerah Irigasi Air Sagu. Jurnal Teknik Sipil, 1(1), 80-93. Google Scholar

Cresswell, J. W. (2017). Research Design: Pendekatan Kualitatif, Kuantitatif, dan Mixed (Edisi Ketiga). Yogyakarta: Pustaka Belajar. Google Scholar

Eyben, Rosalind. (2003). Mainstreaming the social dimension into the overseas development administration: a partial history. Journal of International Development: The Journal of the Development Studies Association, 15(7), 879892. Google Scholar

Kogoya, Teraik, Olfie, Benu, \& Laoh, Olly Esry. (2015). Partisipasi masyarakat terhadap pembangunan infrastruktur jalan desa di kabupaten lanny jaya-papua. Jurnal Berkala Ilmiah Efisiensi, 15(02). Google Scholar

Norhadi, Ahmad, Marzuki, Akhmad, Wicaksono, Luki, \& Yacob, Rendi Addetya. (2015). studi debit aliran pada sungai antasan kelurahan sungai andai Banjarmasin Utara. Poros Teknik, 7(1). Google Scholar

Sari, Dian. (2015). Penerapan Manajemen Aset Pada Daerah Irigasi Pondokwaluh Kabupaten Jember (Studi Kasus di Primer Kencong Timur, Sekunder Besini, Sekunder Gumukmas, dan Sekunder Jati Agung). Google Scholar

Sugiyono, Prof. (2015). Metode penelitian kombinasi (mixed methods). Bandung: Alfabeta, 28. Google Scholar

Widodo, Sri, Suharno, Kun, \& Salahudin, Xander. (2016). Analisis Aliran Air dalam Pipa Bercabang (Junction). Wahana Ilmuwan, 1(1). Google Scholar 
First publication right:

Syntax Literate: Jurnal Ilmiah Indonesia

This article is licensed under:

(c) (i) (2) 